\title{
A Governance Reference Model for Virtual Enterprises
}

\author{
Ricardo J. Rabelo ${ }^{1}$, Scheila N. Costa ${ }^{1}$, and David Romero ${ }^{2,3}$ \\ ${ }^{1}$ Dept. of Automation \& Systems Engineering, Federal University of Santa Catarina, Brazil \\ ${ }^{2}$ Tecnológico de Monterrey, Mexico \\ ${ }^{3}$ Griffith University, Australia \\ ricardo.rabelo@ufsc.br, \{nc.scheila,david.romero.diaz\}@gmail.com
}

\begin{abstract}
During its entire lifecycle the Virtual Enterprise (VE) partners should share a sort of assets and sensible information as well as execute intra- and inter- organizational business processes in a coordinated and secure way, mostly supported via computer networks. VE partners are however independent enterprises and have their own business strategies. Therefore, it is relevant to properly govern a $\mathrm{VE}$ in way to minimize conflicts among its partners and hence the risks for achieving the VE goals. This paper presents a VE governance reference model allowing the instantiation of more concrete governance models for given VEs. An important contribution of this research is the consideration of the economic dimension of governance, not covered in related works.
\end{abstract}

Keywords: Collaborative Networked Organizations, Virtual Enterprises, Governance, Reference Model, Instantiation Approach.

\section{Introduction}

With the increase competition in the global market, enterprises have been open to participate much more actively in strategic alliances. In this context, Collaborative Networked Organizations (CNOs) have arisen as a paradigm to support a number of competitive advantages for all involved organizations, including the exploitation of new market segments and opportunities, costs reduction and risks mitigation [1].

There are many types of CNOs manifestations. This work focuses on the Virtual Enterprise (VE) type. Generally, a VE can be defined as a temporary alliance formed by autonomous, heterogeneous and geographically dispersed enterprises that join their complementary core competences and resources to better attend to a given demand, dismantling itself after finishing all its legal obligations [1]. VEs are mostly originated from long-term strategic alliances, namely Virtual organization Breeding Environments (VBEs). A VBE formally groups organizations in order to provide enough pre-conditions and basic operating rules for collaboration among its members aiming at creating VEs with the most adequate partners in a more agile and trustful way [1].

During its entire lifecycle VE partners should share a sort of assets and sensible information as well as execute intra- and inter- organizational business processes. VE partners are however independent enterprises and have their own business strategies, which creates a complex and intrinsic conflicting VE operation scenario. Therefore, it is of extreme relevance to properly govern a VE in way to minimize conflicts among its members and involved external and hence the risks for achieving VE goals. 
Some related works on VBE and VE governances (e.g. [2], [3] and [4]) assume that a given VE should generally inherit (partially) the governance model from the VBE whose partners belong to. This seems correct as a VBE somehow imposes to its members a set of common principles and operating rules. In spite of that, this paper goes one step forward. It facilitates the instantiation and definition of particular VE governance models, but keeping them aligned to the VBE governance model [2] [3] in order to preserve the VBE values and bylaws [4].

This assumption is grounded both in empirical observations from some real VBEs implementations (e.g. as described in [5]) as well as in literature review (e.g. [6]). Basically, it has been realized that a VE is mostly unique. Even though the good to be produced is similar to someone previously manufactured, VE partners' composition can be totally different. This may happen due to many reasons, such as the eventual unavailability, non-interest or low historical performance of some previous partners in the related past VEs. Besides that, collaborative business opportunity's requirements, customer requests and commercial rules deeply affect many aspects in the way a VE should behave and hence be managed, like as the required legal framework, logistics itineraries and type of logistics partners, the setting-up of the decision model (between partners) and its structure, and the influence of the customer along the general production process. Therefore, an additional and complementary coordination instrument should be created, which is represented by the VE governance model.

Very few works in the literature have tackled the VE governance from that more comprehensive view. It was also observed that the works on networked governance are very abstract (e.g. [2] [7]), creating difficulties for SMEs to deploy them.

As a contribution in this direction and from a more business processes-oriented perspective, this paper presents a proposal of a VE governance reference model. It allows the derivation of concrete governance models for given VEs, defining the actors, relations among them and with the VBE governance model, rules and mechanisms to be used along each phase of the VE lifecycle (creation, operation/ evolution, dissolution) regarding VE partners' rights and duties, and taking the given business demand's characteristics into account.

This paper is organized in five sections. The first one has introduced the problem and the context of the research work. Second section describes the basic concepts of governance in networked enterprises. The third section presents the proposed VE governance reference model. Section fourth illustrates an instantiation of the governance reference model. Section five summarizes some conclusions of the work.

\section{Governance in Networked Enterprises}

Governance in networked enterprises can be defined as "the specification of rules, criteria for decision-making, responsibilities, and boundaries of actions and autonomy for the involved actors. It is created by the own set of organizations to regulate itself. The fundamental role of governance is not managing; but to delimitate/guide the management instead. Actors can use their knowledge within the defined governance framework in way to help organizations to best reaching their common goals [8]". 
Networked enterprises governance have to consider two complementary dimensions: one related to the coordination of the economic activities, and another one to the network structure and coordination of its activities [8]. The essential rationale is that the market and power influence directly the way a network should execute and manage its processes and all related information, and hence on how it should be internally organized to correctly and efficiently respond to that.

There are a number of approaches about networked enterprises governance in the literature regarding the economic dimension, providing different perspectives and classifications in terms of governance strategies. However, almost all of them are in practice devoted to "classical" networks, as VBE-like or more static ones.

Under this dimension and in the context of this research, five works were taken as the theoretical foundation basis to identify the required elements for VE governance and to propose a reference model. They are basically explained below, in a sequence, which corresponds to how they have also evolved along the time.

Williamson [9], for instance, was one of the first ones who identified the relevance of networks, pointing out that the power could no longer be governed by a single enterprise. Storper et al. [10] depicted the power itself among enterprises using two concepts: core (main enterprise) and ring (suppliers). By means of the combination of these concepts they identified four types of governance in terms of power concentration or distribution: all-ring, no-core; core-ring with coordination firm; core-ring with lead firm; and all-core, no-ring. Gereffi [11] has seen the network from the value chain point of view, identifying when the network was fundamentally producer-driven, buyer-driven or information-driven (e-commerce related). In another work, Gereffi [12] complemented this work seeing the network also from the point of view of power relation among buyers and producers as a consequence of the required network's production structure for a given demand. For that, they proposed five other categories of governance types: market, modular value chain, relational value chain, captive value chain and hierarchical. In all these approaches authors assumed a tight connection and a-priori knowledge between the involved enterprises. Provan et al. [13] was one of the first ones who addressed the problem considering the enterprises as a set of totally autonomous and decoupled organizations but that should also work for a common goal. They have identified three basic governance types: shared governance (when the power is more or less equivalent among the members), leader organization governance (when the power is clearly more concentrated on a given single organization), and network management organization governance (when the network delegates the power to an external organization).

Very few works were found out in the literature proposing more concrete means for a VE governance model from the network structure and coordination dimension point of view. Albers [14] has identified two sub-dimensions for that, called structural dimension and instrumental dimension. Structural dimension basically copes with the network structure and which tasks partners should do. Instrumental dimension basically refers to the networked coordination and incentive mechanisms to sustain the collaboration. Albers [14] model is however too abstract, it does not consider anyhow the 'economic dimension', and does not provide any concrete guidelines on how those dimensions should be instantiated to support the network 
operation. In spite of the importance of this contribution, the author considered a classical network, with fixed partners. Dekkers et al. [15] recognizes the influence of the market and external contexts in the way a network is organized, coordinated and managed. However, they do not propose a model for that.

In terms of governance models, Romero et al. [3] tackled governance explicitly from the CNOs point of view, but with a focus on VBE-like networks. This first work has generally identified the structural governance elements that a VBE should have: principles, bylaws and rules. Rules in turn can be of functional (e.g. operational procedures to manage the VBE) and behavioral (e.g. ethical code) natures. In another work, Romero et al. [2] have extended this general model to VEs. Actually, it corresponds to an instantiation from the VBE model and with a focus only in the VE creation phase. That model is however a bit abstract, does not consider the economic dimension, and processes are described at a general level, which creates some difficulties for SMEs to understand how to use and deploy it.

A substantial part consumed in the VE creation process refers to the governance model setting-up [4]. Within this context, the underlying value proposition of this work is to provide more systemized, concrete and transparent means to govern VEs considering those two main dimensions simultaneously. This gives better conditions for faster VE creations as well as for more confidence and trust among partners along the VE lifecycle as long as all roles and rules are clearly defined and agreed.

\section{A Virtual Enterprise Governance Reference Model}

\subsection{VE Governance Model Elements}

Four key aspects are behind the rationale of the proposed VE governance reference model. The first one refers to the consideration of the two fundamental dimensions of governance: economic and structural. The second one refers to considering governance at its essential, i.e. that it does not manage itself, but rather restrains the limits of management. The third one refers to see that the VE governance is influenced by the VBE governance model. The fourth one refers to considering the requirements of VEs, which are different than the other not dynamic networks.

Camarinha et al. [16] points out the following VE main characteristics that then should be supported (requirements) by any VE-related model: $i$ ) VE partners come from another network: a VBE; ii) VE partners are autonomous; iii) VE partners are heterogeneous at several levels; $i v$ ) VE members do not know to each other a priori when they become VE partners; $v$ ) Due to the fact VE partners come from a VBE, a sort of common principles are agreed and hence the trust building problem is mitigated; vi) a VE (and the way partners should behave) can be totally different from another one created in the past to respond to the equivalent business; vii) VE partners have different roles and hence different rights and duties along the VE lifecycle; viii) a VE should be kept alive until all of its legal obligations are ceased.

This last requirement demands for an extension in the classical VE lifecycle [16], with the addition of the "after sale" phase (e.g. maintenance, warranty, devolution and new extra services). This means that a governance model should also embrace a 
set of concrete actions that VE partners should carry out after the "product" (in a broad sense) has been delivered (dissolution phase), assuming that the VE has accomplished the business requirements successfully [17].

Considering those four key aspects above mentioned; Figure 1 shows the proposed VE governance reference model, highlighting the wider framework it is inserted in: as a model that is influenced by the VBE governance model and that behaves according to external business conditions. These conditions are actually affected by the nature of the given collaboration business opportunity, customers, regulations and all external issues that can influence the network from the economic and power perspectives.

Inspired in the work of Romero et al. [2] and Albers [14], the proposed VE governance reference model is composed of four fundamental constructs: Actors, Rules, Mechanisms and Principles.

The basic logic of the proposed model can be understood as: actors will be organized and act along different phases of the VE lifecycle making use of rules and mechanisms, and all such actions should respect the VE and VBE principles. The different actors have roles, rights and duties respected to each VE phase in way to guarantee its correct and good functioning, concerning the business requirements and the economic and power constraints.

Actors represent the involved participants in a VE. Considering the different level of responsibilities actors can have, they can be inter-organizational [15] (e.g. $V E$ manager, VE broker, and VE coordinator) and intra-organizational (e.g. the company manager, an engineer, and a technician).

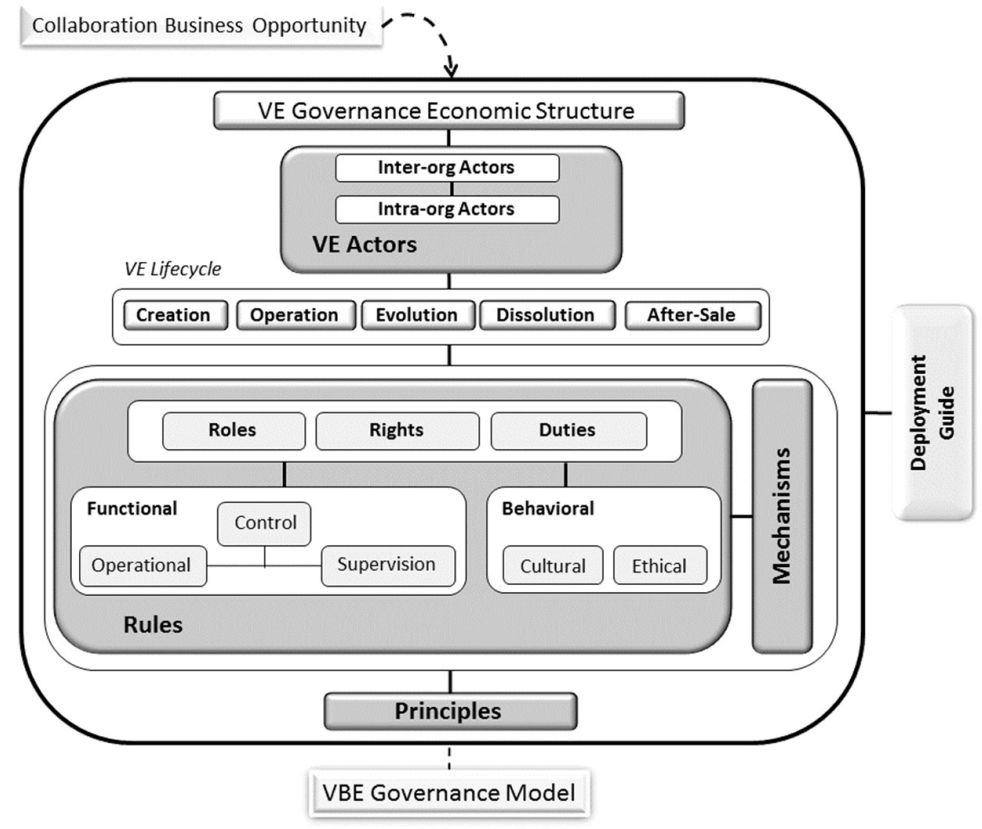

Fig. 1. VE Governance Framework and Reference Model 
Principles represent the underlying values (e.g. honesty, commitment and mutual respect) that companies and people must follow. They usually come from the VBE and can also be complemented with other principles at VE level, depending on the given collaboration business opportunity's requirements. These principles should be somehow reflected in the governance rules. For example, commitment can be "deployed" as rules related to certain type of actor(s) to "send up-to-date information about tasks to the other actors for follow-up purposes" at the VE operation phase.

Rules represent concrete actions that given actors should execute at given VE phase(s) by means of mechanisms respecting predefined principles. Rules are associated to the roles and hence to the rights and duties that VE partners have at the different phases of the VE lifecycle. This means that a given actor may have more than one single role in a given VE. A role is represented by "unitary" actions that given actors can perform (e.g. inform clients about production execution). Depending on how the other governance elements have been decomposed, this exemplified role can be of responsibility of actors VE coordinator and VE manager.

Rules can be of two main categories: functional and behavioral, which in turn are subdivided into operational, control and supervision; and cultural and ethical, respectively. In essence, while functional rules are devoted to help framing the daily operational routine along the VE life (and where control rules are hierarchically above the other two ones), behavioral rules are devoted to people. For example, "supervising the product delivery" is seen as a functional-supervision rule; "sending the information about any delay and the responsible sector as soon as the problem is detected" is seen as a behavioral-cultural rule.

In resume, rules should be handled at a given VE phase by a given actor who has a given role that is settled as his duty, and this only exists because there is another actor(s) who has some rights related to that.

Mechanisms are basically the available or necessary means required to help actors in the rules execution. They can be formed by techniques (e.g. project management methods), software (e.g. groupware systems), devices (e.g. data collectors) and infrastructures (e.g. larger broad-band Internet for some specific situations).

In those hypothetical examples, this would be only possible and correct because (from the economic dimension perspective point of view) the business would have required (regarding the current VBE's members profile) a production structure and governance mode of type relational value chain (when there is a tight connection between the client and producers along the entire production). It would be buyerdriven as the client would have a strong influence all over the process. As the company which got the business (assuming the 'VE coordinator' role, for example) would be clearly the main producer (i.e. core-ring with lead firm), it would be allowed to have the power to ask for qualified information from any VE partner (this would come from a VBE governance model's rule) and then the whole network has to run under the leader organization governance mode.

\subsection{VE Governance Rules Formalization}

An instance of a given VE governance model can have plenty of rules. Having in mind that the most important goal of a governance model is to be indeed followed by 
the involved actors, it is of extreme importance that its rules should be documented. In fact, rules are the element to which all the economic and structural elements converge to and are reflected in.

There are different ways to express and to formalize such kind of rules (which is not the same than modeling business processes). Regarding the reality of SMEs, the formalism should be simple even though less rich. Writing rules textually is difficult but as some rules' details can be easily forgotten. Rules should be easy to understand by typical SME people, to document, to maintain, and to be quickly consulted and checked. In this sense, this work has opted to model rules using the very known and simple $5 \mathrm{~W} 2 \mathrm{H}$ technique. By means of a set of "questions", rules can be comprehensively and formally expressed, as showed in Figure 2.

\begin{tabular}{|l|l|l|}
\hline \multicolumn{1}{|c|}{ Question } & \multicolumn{1}{|c|}{ Description } & \multicolumn{1}{c|}{ Element } \\
\hline What? & It defines the concrete action that has to be done. & $\begin{array}{l}\text { Functional or } \\
\text { Behavioral rule }\end{array}$ \\
\hline Who? & It defines the actor who has the role to do the "what". & Actors and roles \\
\hline When? & $\begin{array}{l}\text { It defines when (the VE lifecycle phase) that the "what" has } \\
\text { to be done by the "who". }\end{array}$ & VE lifecycle phase \\
\hline Where? & $\begin{array}{l}\text { It defines where (general or specific place) the "who" has } \\
\text { to perform the "what" at the phase "when". }\end{array}$ & Physical place \\
\hline Why? & It explains in details the purpose of the action "what". & Aim \\
\hline How? & $\begin{array}{l}\text { It indicates the way (methods, procedures, protocols, etc.) } \\
\text { that the "what" has to be done by the "who" as well as } \\
\text { eventual related performance metrics. }\end{array}$ & Mechanisms \\
\hline How much? & $\begin{array}{l}\text { It gives an indication of the costs (or notes about it) to do } \\
\text { the "what" (if applicable and if values are relevant). }\end{array}$ & Costs \\
\hline
\end{tabular}

Fig. 2. 5W2H technique adapted for the VE governance reference model

\section{Instantiation of the VE Governance Model}

This section presents examples of the instantiation of the proposed VE reference governance model. Actually, this corresponds to a real scenario, based on a case of a Brazilian network of mould-makers called NuFerJ, to which the governance model was applied, tested, and validated. NuFerJ has been found 19 years ago and its members are SMEs, completely independent to each other, although some of its members used to always work with some members in some cases. Since 2010 NuFerJ has started an initiative to (also) work under the VE strategy aiming at enlarging business possibilities (via larger production capacity) and maximizing resources utilization. NuFerJ uses to receive a "package" of moulds. VE partners can then be responsible for an entire mould, part of it, or for some specific operations of it. This VE notion is also communicated to the customers before contracting, i.e. they know the companies that will participate in a given VE.

NuFerJ customers are mainly automotive, electro-electronics and home appliances sectors, from a number of different countries, although Brazilian (large) companies 
are the ones which mostly generate demands. Therefore, NuFerJ - and so VEs that are generated to attend such demands - has to deal with a variable economic environment.

Taking into consideration the governance approaches described in the section 2, NuFerJ "fits" some of them, depending on the collaboration business opportunity, customer, and other general requirements. In order to illustrate a given instance of a derived governance model for a given VE and due to size restrictions of the paper, the example below will take only one "business scenario" and only two rules will be showed. Actually, the current version of NuFerJ VE governance "reference" model is composed of 54 rules that cover important situations over the whole VE lifecycle.

From the governance structural dimension perspective point of view, besides the bylaw, etc., principles of NuFerJ network (so at the VBE level) include honesty (in the sense of always sending trustful information and do not lie during conversations), commitment (partners will indeed put all efforts to keep the business requirements), and collaboration (willingness to help members in the case of problems).

In this example, the general governance "framework" would be classified as buyer-driven, relational value chain and core-ring with coordinating firm.

The two rules below show the VE governance model instantiated in two situations. Figure 3 shows a rule to be used in the VE creation phase when a given partner decides (meaning that it has this degree of autonomy in accordance to the governance 'framework' and expressed in the contract) to subcontract another company to make a specific operation which any of the other members are capable to.

\begin{tabular}{|l|l|}
\hline What & Hire an outside company. Rule: Right-Functional-Operational. \\
\hline \multirow{2}{*}{ Who } & Inter-organizational Actor: VE manager, VE broker, VE customer. \\
\cline { 2 - 3 } Why & Intra-organizational Actor: Member manager. \\
\hline \multirow{2}{*}{ When } & $\begin{array}{l}\text { In order to cope with very specific product's technical requirements. } \\
\text { In the case of any VE partner is no longer capable to fulfill the needed requirements. }\end{array}$ \\
\hline Where & Not applicable. \\
\hline \multirow{2}{*}{ How } & $\begin{array}{l}\text { Following the specific contract clauses. } \\
\text { Mechanisms: Partners'Search and Selection software system }\end{array}$ \\
\hline \multirow{2}{*}{ How much } & $\begin{array}{l}\text { Costs cannot be added to the whole contract and are of responsibility of } \\
\text { the VE partner contractor to handle this. }\end{array}$ \\
\hline
\end{tabular}

Fig. 3. Example 1 of Governance model's rule

Figure 4 shows another situation, of a rule to be used in the VE evolution phase, when the VE manager observes that, after some attempts to solve the problem close to a problematic company that is not working as expected, he is allowed to withdraw the assigned given mould (entirely or part of it) from it. 


\begin{tabular}{|l|l|}
\hline \multirow{2}{*}{ What } & $\begin{array}{l}\text { Withdraw a task, part or entire mould from a given partner. } \\
\text { Rule: Right-Functional-Operational. }\end{array}$ \\
\hline \multirow{2}{*}{ Who } & Inter-organizational Actor: VE manager. \\
\cline { 2 - 3 } Why & Intra- organizational Actor: Member manager. \\
\hline \multirow{2}{*}{ When } & $\begin{array}{l}\text { Evolution phase. When it is realized that a given VE partner is no longer able to keep } \\
\text { producing what it was contracted considering the contract specifications. }\end{array}$ \\
\hline Where & NuFerJ office \\
\hline How & $\begin{array}{l}\text { Following the specific contract clauses. } \\
\text { Mechanisms: groupware and PMBOK project management }\end{array}$ \\
\hline How much & Costs and penalties expressed in the contract clauses. \\
\hline
\end{tabular}

Fig. 4. Example 2 of Governance model's rule

The process of defining the rules is however "manual" and has some degree of subjectivity (although all rules must be agreed among partners before the VE start).

This rational process is reasonably complex to make and involved managers (and even the VBE staff in some cases) are the ones who should analyze the given business scenario and its requirements (from the economic perspective) as well as configure a proper and feasible structure for the VE governance model regarding the VBE governance model (principles, bylaws, etc.) and members' profile. In other words, such manager(s) should know the VBE governance model to "guarantee" that the VE governance model inherits the essentials of that one, and hence that it is aligned with it. The VE governance reference model should then be derived for the given VE and its constructs be instantiated accordingly. Some basic governance model's constructs should be prepared, configured and set up "some time" in advance (depending on the existing conditions) of the VE creation or when it is going to be created.

The 54 used rules can be taken as templates for other derivations as they follow the reference processes and activities typically executed in a VE along its lifecycle [18].

Actually, deploying a VE governance model is far from being trivial. This is even more critical regarding that a typical VBE is mostly composed of SMEs. In order to mitigate the deployment work, the proposed governance framework also provides a deployment guide (not presented here due to paper length restrictions). Roughly, along five macro steps, it leads the person(s) in charge of that to go through the model and create an instance of the VE governance reference model for given VEs. To be noted that such person(s) is actually an actor, who is linked to a given role, and that is linked to the VBE and/or VE governance model.

\section{Conclusions}

This paper has presented a proposal for a VE governance reference model, integrating two referential perspectives: structural and economic. Dealing with VE governance from those two main dimensions simultaneously and providing concrete means to deploy a model in real cases is, however, complex and challenging. The proposed model represents a contribution towards filling up an existing gap in the literature. 
The developed reference model is generic and can be instantiated for different VEs for different business scenarios. The value proposition of this model is concentrated in some perspectives, like faster VE deployment and confidence among VE partners and customers about more formal procedures to minimize VE risks in the accomplishment of its goals.

From the scientific perspective, its main contribution refers to the integration of the economics governance dimension and that the model is very concrete, more formally expressed, and indicates how the model's elements can be instantiated.

Deploying a governance model for given VEs is however not trivial. The analysis of every economic and structural detail of the collaboration business opportunity and deployed VBE demands much experience from the managers. Yet, the agreement about some rules is far from being easy and quick to reach a consensus among the involved actors, requiring many discussions. On the other hand, once reached, the governance model trends to achieve its essential goal: to be followed by all actors, with a more robust commitment, and more customer confidence.

Both VE governance reference model and instances-of it are not completely static once set up. As in any organization, several factors can contribute to change the rules as long as VBE governance model and businesses environments evolve.

The main limitation of the identified rules and view upon the economic dimension is that all information is handled fundamentally from the engineering point of view. Legal, social, management and accounting supporting foundations are not ready "transformed" into rules and will require additional guidelines in the model. Besides that, the model was only evaluated in one network. Therefore, larger evaluations are necessary towards a still more comprehensive reference model. These two issues are the main ones planned to be tackled in the short-term of this research. Another research action refers to evaluate richer modeling formalisms to better capture and express the network dynamics and the governance rules as $5 \mathrm{~W} 2 \mathrm{H}$ is relatively poor. Finally, a deeper research is needed to better identify the conceptual borders between governance and VE coordination tasks in a more global VE management framework.

Acknowledgements. This work has been partially supported by CNPq Brazilian research funding agency.

\section{References}

1. Afsarmanesh, H., Camarinha-Matos, L.M., Ermilova, E.: VBE Reference Framework. In: Camarinha-Matos, L.M., et al. (eds.) Methods and Tools for Collaborative Networked Organizations, pp. 35-68. Springer (2008)

2. Romero, D., Giraldo, J., Galeano, N., Molina, A.: Towards Governance Rules and Bylaws for Virtual Breeding Environments. In: Camarinha-Matos, L.M., Afsarmanesh, H., Novais, P., Analide, C. (eds.) Establishing the Foundation of Collaborative Networks. IFIP, vol. 243, pp. 93-102. Springer, Boston (2007)

3. Romero, D., Galeano, N., Molina, A.: VO Breeding Environments Value Systems, Business Models and Governance Rules. In: Camarinha-Matos, L.M., et al. (eds.) Methods and Tools for Collaborative Networked Organizations, pp. 69-90. Springer (2008) 
4. Romero, D., Oliveira, A., Camarinha-Matos, L.M., Molina, A.: The Virtual Enterprise from a Governance Perspective. In: Camarinha-Matos, L.M., Pereira, P., Ribeiro, L. (eds.) DoCEIS 2010. IFIP AICT, vol. 314, pp. 73-82. Springer, Heidelberg (2010)

5. Special Panel Sessions on Real Collaborative Networkd Organisations, http://www . slidesshare.net/davidromerodiaz

6. Romero, D., Rabelo, R.J., Molina, A.: Special Issue on Collaborative Networks as Modern Industrial Organizations: Real Case Studies. International Journal of Computer Integrated Manufacturing 26(1-2) (2012)

7. Sun, G.-Q., Lan, J.-Y.: A Theoretical Framework of the Governance Mechanisms. In: Proceedings Int. Conference on Management Science and Engineering, pp. 947-951 (2006)

8. Roth, A.L., Wegner, D., Padula, A.D.: Differences and Inter-Relations of Governance Concepts and Horizontal Networked Enterprises Management. Journal of Administration 47(1), 112-123 (2012) (in Portuguese)

9. Williamson, O.: The Mechanisms of Governance. Oxford University Press (1996)

10. Storper, M., Harrison, B.: Flexibility, Hierarchy and Regional Development: The Changing Structure of Industrial Production Systems and their Forms of Governance in the 1990s. Research Policy 20, 407-422 (1991)

11. Gereffi, G.: Shifting Governance Structures in Global Commodity Chains, with Special Reference to the Internet. American Behavioral Scientist 44(10), 1616-1637 (2001)

12. Gereffi, G., Humphrey, J., Sturgeon, T.: The Governance of Global Value Chains. Review of International Political Economy 12(1), 78-104 (2005)

13. Provan, K.G., Kenis, P.: Modes of Network Governance: Structure, Management, and Effectiveness. J. Public Administration Research and Theory 18(2), 229-252 (2008)

14. Albers, S.: Configurations of Alliance Governance Systems. Schmalenbach Business Review 62, 204-233 (2010)

15. Dekkers, R., Luttervelt, C.A.: Industrial Networks: Capturing changeability? International Journal of Networking and Virtual Organizations 3(1), 1-24 (2006)

16. Camarinha-Matos, L.M., Afsarmanesh, H.: Collaboraive Networks: A New Scientific Discipline. Journal of Intelligent Manufacturing 16, 439-452 (2005)

17. Elhabib, N., Boucher, X., Peillon, S.: Engineering of service oriented collaborative network. In: Camarinha-Matos, L.M., Boucher, X., Afsarmanesh, H. (eds.) PRO-VE 2010. IFIP AICT, vol. 336, pp. 461-468. Springer, Heidelberg (2010)

18. Romero, D., Molina, A.: VO Breeding Environments \& Virtual Organizations Integral Business Process Management Framework. Inf. Systems Frontier (11), 569-597 (2009) 